\title{
Pharmacogenetics: transforming clinical medicine
}

WG Newman

Clinical Senior Lecturer, Genetic Medicine, St Mary's Hospital, Manchester Academic Health Sciences Centre (MAHSC), University of Manchester, UK

This review is based on a presentation given by Dr Newman at the RCPE Genetics Symposium on 20 April 2012.

ABSTRACT Pharmacogenetics, the study of genetic variation relevant to drug metabolism, is a rapidly evolving area of medicine.This brief review will consider some of the recent advances where inherited genetic variants have been associated with either drug efficacy or toxicity. Examples of where pharmacogenetic testing has been adopted into clinical practice will be provided as well as a look at its likely development over the next decade. Finally, the large increase in genetic testing of tumour tissue samples to predict response to molecularly targeted treatments in cancer will be considered.
Correspondence to W Newman Genetic Medicine, St Mary's Hospital, Manchester Academic Health Sciences Centre (MAHSC), University of Manchester, Manchester MI3 9WL, UK

tel. $+44(0) 1612764150$

e-mail

william.newman@manchester.ac.uk

KEYWORDS Pharmacogenetics, adverse drug reactions, oncology,

pharmacogenomics, efficacy

DECLARATION OF INTERESTS No conflicts of interest declared.

Terms such as pharmacogenetics, pharmacogenomics, personalised medicine and stratified medicine have all been used interchangeably over the past few years to describe a revolution that is occurring in medicine. Every day throughout the UK thousands of individuals undergo genetic tests to establish the most effective or safest medication for their condition. However, pharmacogenetics is not a new concept. Over fifty years ago reports emerged of haemolytic anaemia in Americans on antimalarial medication and its relationship with glucose 6-phosphate dehydrogenase deficiency.' It was at this time that Friedrich Vogel first coined the term 'pharmacogenetics', defining it as the 'study of the role of genetics in drug response'.2 Significant advances were made in the 1970s with studies undertaken to characterise the cytochrome P450 enzyme family. These liver enzymes are key factors in the first pass metabolism of the majority of drugs and overactivity or deficiency of specific members of this family have been associated with a range of adverse drug reactions. It is only over the last decade that the knowledge gained through thousands of studies has started to be applied in clinical practice.

The major motivation behind pharmacogenomics is to use genetic information to reduce the likelihood of adverse drug reactions (ADRs) and to improve the likelihood of individuals responding effectively to their medication. Pharmaceutical companies have invested millions of dollars undertaking genetic profiling to improve the drug development pipeline to manufacture drugs less likely to cause serious ADRs, notably drug induced liver injury and long QT syndrome. These ADRs cause their drugs to fail at a late stage in trial development or to be withdrawn from the marketplace after licensing. There is also the possibility that drugs that have already failed during development or been withdrawn may be reinstated if a patient subgroup likely to respond and at low/no risk of side-effects is identified.

\section{ADVERSE DRUG REACTIONS}

Adverse drug reactions are a significant cause of morbidity and mortality. A large prospective study of over 18,000 patients attending hospitals in the North West of England revealed that $6.5 \%$ of patients presented due to an ADR. ${ }^{3}$ Furthermore, a study of hospital inpatients identified ADRs in nearly $15 \%$ of patients following admission. ${ }^{4}$ Most of these adverse reactions are due to non-adherence, polypharmacy leading to drug interactions, inaccurate doses or prescription of the wrong medication for the clinical indication. However, an important and increasingly recognised subset of serious ADRs is due to genetic factors.

\section{THIOPURINE PHARMACOGENETICS}

The pharmacogenetics of the thiopurine drugs azathioprine and 6-mercaptopurine have been at the forefront of this discipline.Thiopurines are used routinely in the management of inflammatory diseases, including inflammatory bowel disease, and in the maintenance phase of the treatment of childhood leukaemia. However, the use of thiopurines is limited by intolerance to a range of side-effects including nausea, vomiting, flu-like symptoms and, importantly, neutropenia. The initial description of individuals deficient in thiopurine methyltransferase (TPMT) enzyme activity who experience severe neutropenia emerged over 30 years ago., ${ }^{5,6}$ Over the 
ensuing years controversy continued about the clinical utility of testing and the reluctance to adopt routine testing prior to thiopurine prescription. ${ }^{7}$ Approximately one in 300 individuals are deficient for TPMT enzyme activity. The evidence is compelling that these people will experience a serious ADR (neutropaenia) if exposed to standard doses of thiopurines. Therefore, genotyping or enzyme assays should be performed to identify individuals deficient in TPMT and they should be given very low doses of thiopurines or an alternative drug. However, not all neutropaenia secondary to thiopurines can be predicted by TPMT testing and routine full blood count monitoring is therefore still required for all patients on this group of drugs. Many reports indicated that individuals heterozygous for a TPMT loss of function variant and therefore with intermediate enzyme activity, were also at an increased risk of ADRs. ${ }^{8}$ However, in a prospective randomised controlled trial of adults with inflammatory diseases treated with azathioprine, there was no evidence of an increased frequency of ADRs in this group.' Despite the initial delay in the use of TPMT testing in the UK, over the past five years there has been a dramatic increase due to changes in professional clinical guidelines, technological advances facilitating cheap and rapid enzyme analysis and growing physician awareness. ${ }^{10}$

In contrast to the delay in TPMT testing, there was a rapid adoption of testing related to the highly active antiretroviral therapy, abacavir. It was introduced for human immunodeficiency virus (HIV) treatment in 1999 as single agent or in combination. Approximately 5-8\% of patients exposed to abacavir developed drug hypersensitivity in the first six weeks of use. Individuals presented with characteristic nausea, fever, vomiting, rash and headache. Importantly, the drug was potentially fatal on re-exposure. Mallal and colleagues identified a strong association between the HLA-B*570I allele and hypersensitivity." The test was rapidly adopted as a prescreen in Australia and to reinforce the evidence of the association, GlaxoSmithKline designed and executed a randomised controlled trial. A total of I,800 individuals were randomised equally to either HLA genotyping or standard care. Individuals in the intervention arm identified as carrying the HLA-B*570I allele were given an alternative antiretroviral agent. The results showed a complete absence of genuine hypersensitivity reactions in the genotyping arm and led to recommendations by the US Food and Drug Administration (FDA) and European Medicines Agency (EMEA) to mandate HLA$B * 570$ I genotyping prior to abacavir prescription. ${ }^{12}$

\section{ANTI-EPILEPTIC DRUGS}

A study among Han Chinese in 2004 demonstrated that all individuals affected by the rare and severe skin reaction Stevens-Johnson syndrome (SJS) that can occur on exposure to the anti-epileptic drug carbamazepine carried the $H L A-B^{*} / 502$ allele. ${ }^{13}$ This allele is not present in people of European ancestry. The results led to recommendations by the FDA and EMEA that all patients of East Asian origin should have $H L A-B * 1502$ testing prior to receiving carbamazepine treatment. $A$ recent study in Europeans with a range of different sideeffects from carbamazepine demonstrated an association with another HLA genotype, HLA-A*3 IOI. ${ }^{14}$

\section{ANTICOAGULANTS}

Warfarin is the second most common cause of ADRs. ${ }^{3}$ Thousands of patients undergo anticoagulation to prevent thrombosis-related disease. Standard initial treatment previously involved a dose of $10 \mathrm{mg}$ followed by doses of $5 \mathrm{mg}$ for the next two days, prior to testing the international normalised ratio (INR). This approach led to erratic under-anticoagulation in some and dramatic over-anticoagulation in others. Incorporation of clinical parameters including smoking status, age, gender and co-medication helped to refine the dosing amount and optimise outcome. Recent association studies, including genome-wide association studies (GWAS), have indicated that variants in VKORCI and CYP2C9 especially contribute to the effectiveness of anticoagulation with warfarin. ${ }^{15}$ Online algorithms (www.warfarindosing.org) and downloadable apps including genotypic data are available to quickly predict the optimum dose of warfarin. An evaluation by the International Warfarin Pharmacogenetic Consortium compared the value of adding genotypic information into the clinical algorithm with outcomes based on either standard dosing or dosing using clinical parameters. ${ }^{16}$ This study showed a significant reduction in ADRs when the pharmacogenetic data was added to predict the starting doses of warfarin. A number of randomised controlled trials are currently underway worldwide to examine the clinical utility of introducing pharmacogenetic testing for warfarin. One issue that is particularly important for testing warfarin and many other drugs is the turnaround time required to generate genetic testing results. Ideally, for simple analyses, point of care tests could generate results within minutes, leading to minimal delays before accurate, safe prescription.

\section{POINT OF CARE TESTING}

In 1993 a mutation in the mitochondrial genome (m. I555A>G) was found to be associated with profound, irreversible sensorineural deafness following exposure to aminoglycosides. ${ }^{17}$ Approximately one in 500 individuals carries this mutation which confers a very high risk of aminogycoside-induced deafness. ${ }^{18}$ Currently, gentamicin is mostly used in children on neonatal units where delays of two or three days for a genetic test 
result are unacceptable for a child who is septicaemic. Therefore point of care testing, where a genotype can be rapidly realised from a blood spot or saliva sample at the bedside would provide this key information in a clinically relevant time and ensure gentamicin or other aminoglycosides could be avoided in at-risk children.

\section{ADVANCES IN PHARMACOGENETIC TESTING}

Over the coming years it is likely that the most significant advances will be made in defining the causes of severe ADRs. As we have seen, these pose a major health burden. The International Serious Adverse Event Consortium (www.saeconsortium.org) is a publicprivate investor partnership undertaking an ambitious programme of work to define the causes of some of the ADRs that lead to drugs being withdrawn from the market, including drug-induced liver injury (DILI), long QT syndrome and serious skin reactions. Notable successes have already been achieved through the collection of highly phenotyped cohorts where genomewide association studies (GWAS) have revealed strong genotypic relationships. A recent example is the identification of the association between HLA-B*570I and flucloxacillin, causing DILI. ${ }^{19}$ Interestingly, this is not a relationship that can be extrapolated, as carrying the $H L A-B * 570$ I allele is not associated with DILI caused by other medications, including non-steroidal antiinflammatory drugs.

One of the big challenges of modern medicine is distilling the important information generated by research studies from those findings that have less evidence of clinical benefit. In pharmacogenetics there have been numerous association studies which have been underpowered, poorly designed and not replicated. The Clinical Pharmacogenetics Implementation Consortium (CPIC) of the Pharmacogenomics Research Network has been established where experts in genetics, pharmacology and medicine assess the evidence base for the adoption of pharmacogenetic testing and draw up specific guidelines. ${ }^{20}$

New DNA sequencing platforms are now able to generate affordable, rapid whole genome or exome sequence data from individuals. Some initial studies have highlighted the implications for pharmacogenetics where variants in genes known to be important in drug metabolism have been identified. ${ }^{21}$ The challenges of effectively managing this data and providing people with accurate actionable information is yet to be realised.

\section{MOLECULAR ONCOLOGY}

The identification of acquired (somatic) mutations in tumours has also been facilitated by new sequencing and genotyping technologies. Large-scale international projects are underway to characterise the somatic mutations that occur in primary and metastatic tumours to establish their molecular profiles. Such information will help in the understanding of the pathogenesis of the different tumour types, the reasons predisposing to metastasis and provide novel targets for therapeutic intervention. The success of this approach has been seen with drugs to target the tyrosine kinase receptor family. The earliest example of molecularly-targeted treatments in cancer emerged with the development of trastuzumab (herceptin), a monoclonal antibody which is effective in the approximately $30 \%$ of women with breast cancer with overexpression (amplification) of the HER2 receptor. Breast tumour tissue is routinely analysed by immunohistochemistry and fluorescent in situ hybridisation (FISH) to determine HER2 status and the appropriateness of trastuzumab treatment.

In the late 1990s, activating mutations in the CKIT gene encoding a tyrosine kinase receptor were identified in rare cancers called gastrointestinal stromal tumours (GISTs). ${ }^{22}$ These are soft-tissue sarcomas arising from mesenchymal stem cells in the gastrointestinal tract. Imatinib (gleevec) was identified as a small molecule inhibitor of c-Kit and reports emerged of its dramatic efficacy in patients with metastatic GIST and rapid regulatory approval followed. ${ }^{23}$

Activating mutations in CKIT ( 85\%) and PDGFRA (I0$15 \%)$ have been identified in the majority of GISTs. Genetic testing of tumours for CKIT and PDGFRA can provide diagnostic and prognostic information (patients with mutations in PDGFRA have a better outcome and mutations in different exons in CKIT are associated with different outcomes). Furthermore, genetic testing can provide important information about the likelihood of treatment response, for example the specific position of the mutation in CKIT predicts the outcome of imatinib treatment, where patients with a mutation in exon 9 require an increased dose. This genetic information allows the selection of the optimum treatment and also avoids unnecessary costs in individuals with tumours bearing mutations that suggest resistance to treatment.

\begin{tabular}{|c|c|c|c|}
\hline Gene & Variant(s) & Cancer & Drug \\
\hline CKIT & Exons 9 and $1 \mathrm{I}$ & GIST & Imatinib \\
\hline PDGFRA & Exon 18 & GIST & Imatinib \\
\hline EGFR & Exons |8-2| & NSCLC & $\begin{array}{l}\text { Gefitinib and } \\
\text { erlotinib }\end{array}$ \\
\hline KRAS & $\begin{array}{l}\text { Codons } 12,13 \\
\text { and } 61\end{array}$ & $\begin{array}{l}\text { colorectal } \\
\text { cancer }\end{array}$ & $\begin{array}{l}\text { Cetuximab and } \\
\text { panitumumab }\end{array}$ \\
\hline$B R A F$ & V600E & melanoma & Vemurafenib \\
\hline EML4-ALK & $\begin{array}{l}\text { Fusion } \\
\text { oncogene }\end{array}$ & NSCLC & Crizotinib \\
\hline
\end{tabular}


Numerous other targeted drugs have been developed over the past decade including those for non-small cell lung cancer, ${ }^{24-26}$ colorectal cancer ${ }^{27,28}$ and malignant melanoma $^{29}$ (Table I). Testing of these tumour types for somatic mutations is a routine part of the oncology treatment workup. Testing for further tumour types and different genes will grow exponentially over the next few years. Technological advances mean that tumours will be profiled for mutations across a panel of genes to determine the optimum treatment pathway. Numerous challenges still remain however. Tumour biopsy samples are often very small or unobtainable and working with very small amounts of tissue, which is often formalinfixed in paraffin, and a heterogeneous mix of normal and cancer cells requires further optimisation. Many groups are developing approaches whereby tumour DNA circulating freely in the blood or tumour cells in the blood can be isolated and genetic analyses undertaken as a surrogate of the primary tumour.

These are exciting times in molecular medicine where the power of new genetic technologies is being harnessed to provide optimum treatments to patients. The era of personalised medicine is upon us.

\section{REFERENCES}

I Beutler E, Dern RJ, Flanagan CL et al. The hemolytic effect of primaquine.VII. Biochemical studies of drug-sensitive erythrocytes. J Lab Clin Med 1955; 45:286-95.

2 Vogel F. [Moderne problem der humangenetik]. Ergeb Inn Med U Kinderheilk 1959; 12:52-I25. German.

3 Pirmohamed $\mathrm{M}$, James $\mathrm{S}$, Meakin $\mathrm{S}$ et al. Adverse drug reactions as cause of admission to hospital: prospective analysis of 18,820 patients. BM] 2004; 329:15-9. http://dx.doi.org//0.1 I36/bmj.329.7456. I5

4 Davies EC, Green CF, Taylor S et al.Adverse drug reactions in hospital in-patients: a prospective analysis of 3695 patient-episodes. PLoS One 2009; 4:e4439. http://dx.doi.org/I0.137I/journal.pone.0004439

5 Weinshilboum RM, Sladek SL. Mercaptopurine pharmacogenetics: monogenic inheritance of erythrocyte thiopurine methyltransferase activity. Am J Hum Genet 1980; 32:65 I-62.

6 Lennard L, van Loon JA, Weinshilboum RM. Pharmacogenetics of acute azathioprine toxicity: relationship to thiopurine methyltransferase genetic polymorphism. Clin Pharmacol Ther 1989 46: I49-54. http://dx.doi.org/I0.1038/clpt.1989.119

7 Fargher EA,Tricker K,NewmanW et al.Current use of pharmacogenetic testing: a national survey of thiopurine methyltransferase testing prior to azathioprine prescription.J Clin Pharm Ther 2007; 32:187-95. http:// dx.doi.org/I0.IIII/j.1365-27/0.2007.00805.x

8 Higgs JE, Payne K, Roberts $C$ et al. Are patients with intermediate TPMT activity at increased risk of myelosuppression when taking thiopurine medications? Pharmacogenomics 2010; 11:177-88. http://dx.doi.org//0.2217/pgs.09.155

9 Newman WG, Payne K, Tricker K et al. A pragmatic randomized controlled trial of thiopurine methyltransferase genotyping prior to azathioprine treatment: the TARGET study. Pharmacogenomics 20II; 12:8I5-26. http://dx.doi.org/I 0.22I I/pgs. II.32

10 Ferraldeschi R, Newman WG. Pharmacogenetics and pharmacogenomics: a clinical reality. Ann Clin Biochem 2011; 48:4 I0-7. http://dx.doi.org/I0.1258/acb.20II.0II084

II Mallal S, Nolan D, Witt $C$ et al. Association between presence of HLA-B*570I, HLA-DR7, and HLA-DQ3 and hypersensitivity to HIV-I reverse-transcriptase inhibitor abacavir. The Lancet 2002; 359:727-32. http://dx.doi.org//0.1016/S0I40-6736(02)07873-X

I2 Mallal S, Phillips E, Carosi G et al. HLA-B*570I screening for hypersensitivity to abacavir. N Engl J Med 2008; 358:568-79. http:// dx.doi.org/I0.1056/NEJMoa0706/35

13 Chung WH, Hung SI, Hong HS et al. Medical genetics: a marker for Stevens-Johnson syndrome. Nature 2004; 428:486. http://dx.doi, org/10.1038/428486a

14 McCormack M, Alfirevic A, Bourgeois S et al. HLA-A*3I0I and carbamazepine-induced hypersensitivity reactions in Europeans. $N$ Engl J Med 20II; 364:II34-43. http://dx.doi.org//0.1056/ NEJMoa I0I3297

15 Takeuchi F, McGinnis R, Bourgeois $S$ et al. A genome-wide association study confirms VKORCI, CYP2C9, and CYP4F2 as principal genetic determinants of warfarin dose. PLoS Genet 2009; 5:el000433. http://dx.doi.org//0.137//journal.pgen.1000433

16 Klein TE, Altman RB, Eriksson $\mathrm{N}$ et al. Estimation of the warfarin dose with clinical and pharmacogenetic data. N Engl J Med 2009; 360:753-64. http://dx.doi.org//0.1056/NEJMoa0809329

17 Prezant TR,Agapian JV, Bohlman MC et al. Mitochondrial ribosomal RNA mutation associated with both antibiotic-induced and nonsyndromic deafness. Nat Genet 1993; 4:289-94. http://dx.doi. org/10.1038/ng0793-289

18 Bitner-Glindzicz M, Pembrey M, Duncan A et al. Prevalence of mitochondrial I555A-->G mutation in European children. $N$ Engl J Med 2009; 360:640-2. http://dx.doi.org/l0.1056/NEJMc0806396

19 Daly AK, Donaldson PT, Bhatnagar P et al. HLA-B*570I genotype is a major determinant of drug-induced liver injury due to flucloxacillin. Nat Genet 2009; 4I:816-9. http://dx.doi.org//0.1038/ ng.379

20 CPIC: Clinical Pharmacogenetics Implementation Consortium of the Pharmacogenomics Research Network. Clin Pharmacol Ther 201 I; 89:464-7. http://dx.doi.org/l0.1038/clpt.2010.279

2I Ashley EA, Butte AJ, Wheeler MT et al. Clinical assessment incorporating a personal genome. The Lancet 2010; 375:1525-35. http://dx.doi.org/l0.1016/S0I40-6736(10)60452-7

22 Hirota S, Isozaki K, Moriyama $Y$ et al. Gain-of-function mutations of c-kit in human gastrointestinal stromal tumors. Science 1998; 279:577-80. http://dx.doi.org//0.1 / 26/science.279.5350.577

23 Joensuu $H$, Roberts PJ, Sarlomo-Rikala $M$ et al. Effect of the tyrosine kinase inhibitor STI57I in a patient with a metastatic gastrointestinal stromal tumor. N Engl J Med 200I; 344:1052-56. http://dx.doi.org/I0.1056/NEJM20010405344/404

24 Paez JG, Jänne PA, Lee JC et al. EGFR mutations in lung cancer: correlation with clinical response to gefitinib therapy. Science 2004; 304:1497-500. http://dx.doi.org//0.1 I26/science.10993/4

25 Lynch TJ, Bell DW, Sordella R et al. Activating mutations in the epidermal growth factor receptor underlying responsiveness of non-small-cell lung cancer to gefitinib. N Engl J Med 2004; 350:2 129-39. http://dx.doi.org//0.1056/NEJMoa040938

26 Mok TS, Wu YL, Thongprasert S et al. Gefitinib or carboplatinpaclitaxel in pulmonary adenocarcinoma. N Engl J Med 2009; 361:947-57. http://dx.doi.org/I0.1056/NEJMoa08I0699

27 Karapetis CS, Khambata-Ford S, Jonker DJ et al. K-ras mutations and benefit from cetuximab in advanced colorectal cancer. $N$ Engl J Med 2008; 359:1757-65. http://dx.doi.org//0.1056/NEJMoa0804385

28 Van Cutsem E, Köhne $\mathrm{CH}$, Hitre $\mathrm{E}$ et al. Cetuximab and chemotherapy as initial treatment for metastatic colorectal cancer. $N$ Engl J Med 2009; 360:1408-17. http://dx.doi.org//0.1056/ NEJMoa08050I9

29 Chapman PB, Hauschild A, Robert $C$ et al. Improved survival with vemurafenib in melanoma with BRAFV600E mutation. $N$ Engl J Med 20I I; 364:2507-16. http://dx.doi.org/I0.1056/NEJMoal I 03782 